\title{
LOS CUENTOS MISÓGINOS DE MAIMON GALLIPAPA
}

ÁNGELES NAVARRO PEIRO Universidad Complutense. Madrid

Poco es lo que se sabe acerca de este autor, quizás tan sólo su nombre. Las tres sátiras que se le atribuyen aparecieron en la primera edición del Sefer $S a^{\complement} a$ šu $^{c} \hat{\imath} m$ de Yosef ben Zabarra ' a continuación del texto hebreo de dicha obra. Israel Davidson, editor del libro de Zabarra ${ }^{2}$, las publicó atribuyéndoselas a dicho autor ${ }^{3}$. Sin embargo, H. Schirmann ${ }^{4}$ identificó como autor de estas obritas satíricas a Maimon Gallipapa, originario probablemente de la región aragonesa o catalana y que al parecer vivió al final del s. XIV. Las obras que se atribuyen a Gallipapa son las siguientes: Ma'amarim ha-rofe’ $\imath m$, sátira contra los médicos que parodia «Los aforismos de Hipócrates"; Neder 'almanâ, donde se describe de modo general a la viuda que se consuela rápidamente de la muerte de su marido; y por último la obra de la que nos vamos a ocupar: Ma’amar midyenê 'iššâ, título sacado de Prov 19,13 y que trata de las querellas provocadas por las mujeres. Si bien las dos primeras sátiras mencionadas están escritas en el estilo de la narración literaria hispanohebrea, es decir, en prosa rimada; en la última citada tan sólo se utiliza la rima ocasionalmente, aunque contiene algunos versos intercalados entre la prosa llana y hace amplio uso de las citas de versículos bíblicos, recursos también característicos de la narración literaria.

La obrita comienza con una breve introducción en la cual el autor justifica su composición

\footnotetext{
1 Constantinopla 1577.

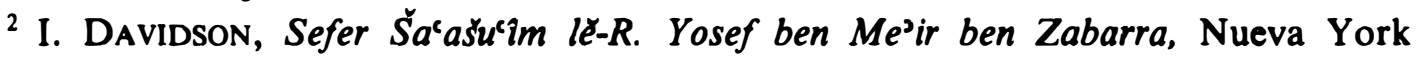
1914 [reimpr. 1925].

${ }^{3}$ I. DAvidson, Salos halasot

${ }^{4}$ Ha-sird ha-cibritị bi-Sĕfarad u-bé-Provence, II, Jerusalén-Tel Aviv 1956, pág. 547.
} 
por las muchas penas y fatigas, por tantas clases variadas, nuevas y viejas, de maldad de la mujer

y solicita la ayuda de Dios. A continuación se suceden consideraciones en contra de la mujer, alternadas con cuentos o ejemplos, algunos muy breves, introducidos por el término mašal. Tales relatos versan sobre la mala mujer, 'išša rá $a^{c} \hat{a}$. Concluye el texto con la queja del autor por la mujer que le ha tocado en suerte, ya que ella le hace la vida imposible, como puede deducirse de sus palabras:

En cuanto a mí, mi oración se dirige a ti, oh Señor, en el momento propicio ${ }^{5}$, por eso te ruego en tiempo de desgracia ${ }^{6}$. Yo encuentro más amarga que la muerte a la mujer '. Presento ante ti mi súplica ${ }^{8}$, oh Dios, el rey, el médico fiel, para librar de la muerte a mi alma ${ }^{9}$. La mujer que pusiste junto a mí ${ }^{10}$ traje de desprecio y orgullo 11 viste, de entre los que me aman me ha expulsado. Procede obstinadamente en contra mía ${ }^{12}$, mi rostro se ha oscurecido más que el hollín ${ }^{13}$. A media noche se levanta para maldecirme, también en la vigilia de la mañana para insultarme. Cada día maquina el mal contra mí ${ }^{14}$, busca querella ${ }^{15}$ a todas horas. Todos mis días son dolores ${ }^{16}$ y mis años penas, incluso los sábados y días de fiesta. En lugar de alegría, tengo aflicción y lamento. En lugar de gozo, sobreviene la angustia. En lugar de júbilo, muerte y desgracia. Desde que estoy con ella no ha cesado"de luchar. No puedo vivir a salvo ni en paz, no hallo reposo... ${ }^{17}$.

En lo que respecta al tema, se podría encuadrar esta composición dentro de la corriente de escritos misóginos medievales, cuyo más destacado representante dentro de la literatura hispanohebrea es el

${ }^{5}$ Sal 69,14 .

${ }^{6}$ Cf. Sal 32,6

7 Ecl 7,26.

${ }^{8}$ Cf. Jer 38,26.

9 Cf. Sal 33,19.

${ }^{10}$ Gen 3,12.

1 Cf. Sal 31,19.

12 Cf. Lev 26,27.

13 Cf. Lam 4,8.

${ }^{14}$ Cf. Prov 3,29.

15 Cf. $2 \operatorname{Re} 5,7$.

16 Cf. Ecl 2,23.

17 Texto hebreo in I. Davidson, Šaloš pág. 31. 
Minhạ Yĕhudâ śone’ ha-našim de Yěhudah ibn Šabbětay (ss. XIIXIII). De hecho, las reflexiones o sentencias en contra de la mujer que aparecen intercaladas entre los cuentos del Ma'amar midyĕnê 'išša de Maimon Gallipapa son similares a las que Ibn Sabbětay pone en boca del anciano Tahkěmônî cuando previene a su hijo Zerah en contra de la mujer y del matrimonio ${ }^{18}$. Sin embargo, hay que tener en cuenta que muchas de esas expresiones tienen su fuente de inspiración en determinados versículos bíblicos o sentencias talmúdicas como las contenidas, por ejemplo, en Yěbamôt $63 \mathrm{~b}$. Debido a ello no se puede establecer con certeza la influencia de un autor en otro, aunque bien es cierto que la obra de Ibn Sabbětay gozó de una gran difusión, como lo prueban los numerosos manuscritos en que se ha conservado, y por ello no hay que descartar la posibilidad de que Maimon Gallipapa tuviera presente el Minhat Yěhudâ al redactar su sátira contra las mujeres. Por otra parte, hay que señalar también que Ibn Sabbětay dirige sus críticas en el Minhat Yěhudá contra la mujer y el matrimonio en general; Gallipapa, por el contrario, se cuida mucho en casi toda la obra de limitar el

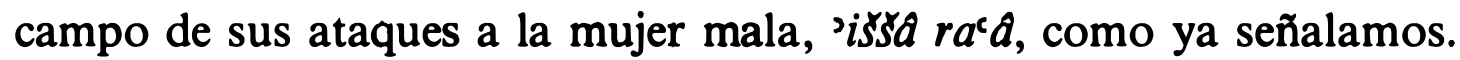
Así se expresa Maimon Gallipapa:

... cualquier mal, pero no la compañía de una mujer ${ }^{19}$. Una mujer mala es caries de los huesos ${ }^{20}$, iqué peligroso es que habite el hombre con ella! En todo lugar donde ella pone los ojos hay o muerte o miseria. Su lengua es una flecha afilada, sus labios fuego y azufre, sus dientes hierro y bronce, ¡brasas encendidas brotan de ella! Su palabra es veneno, el aliento de su boca contamina el aire, una tumba abierta es su garganta... ${ }^{21}$. Mordedura de serpiente y alacrán, pero no mordedura de mujer mala. No hay infierno como una mujer mala, ella es más cruel que los golpes de los tormentos... En toda perfección he visto un límite ${ }^{22}$, pero no para la maldad de la mujer. No tiene juicio, ni ciencia, ni remedio. ¿Para quién son los

${ }^{18} \mathrm{El}$ texto hebreo de esta obra fue publicado por A. Ashrenazi en Tacam Zéqenim, Frankfurt a.M. 1854, págs. 1-12. La traducción castellana del mencionado fragmento de esta obra de Ibn Sabbetay se puede encontrar en A. NAVARRo Peiro, Narrativa hispanohebrea, Córdoba 1988, págs. 172-176.

19 Compárese con Šbb 11a: "Cualquier mal es preferible a una mala mujer».

${ }^{20}$ Cf. Prov 14,30, donde se dice de la envidia.

${ }^{21}$ Texto hebreo en I. Davidson, Šaloš, pág. 26.

${ }^{22}$ Sal 119,96. 
ayes?, ¿para quién los gemidos?, ¿para quién los golpes? ${ }^{23}$ Para el que se casa con una mujer mala. Mejor le será al hombre vivir con una serpiente en el mismo cesto ${ }^{24}$ y no con ella. Elige la muerte, pero no te unas con una mala mujer... Toparse con osa despojada de sus oseznos ${ }^{25}$ y no con una mala mujer. Cualquier héroe se debilitará ante la fuerza de su maldad, aunque ella sea débil. Llamarada de desprecio y ruido de truenos es su voz. Piedras de granizo y hielo son sus dichos. Lluvia que arrasa ${ }^{26}$ y torrente desbordado ${ }^{27}$ es su consejo... ${ }^{28}$.

Al final de la obra Maimon Gallipapa, como ya apuntamos, expone sus quejas contra su propia mujer. En este aspecto su mensaje diverge también del de Ibn Sabbětay, que encuentra para su misógino Minhạ Y Yěhudâ una salida muy airosa y poco comprometida, ya que como epílogo de la obra aduce que todo es una pura invención suya:

"Ninguno de todos esos de quienes hablan fue creado, sino que son pura invención mía y sobre falsas bases se han vertido sus cimientos. Amo a mi mujer y a mis hijos más que todos los que me precedieron" ${ }^{29}$.

Además, aparte del núcleo temático misógino, no hay ninguna afinidad estructural entre las dos obras, pues el Minhat Yěhudâ se puede catalogar como una novela que desarrolla una narración lineal, sin ningún relato insertado, mientras que, como hemos señalado, la sátira de Gallipapa reúne unos cuantos relatos breves en contra de las malas mujeres, precedidos y seguidos de sentencias misóginas.

Ofrecemos a continuación la traducción castellana de uno de

\footnotetext{
${ }^{23}$ Prov 23,29.

24 Ver Ket 72a.

${ }^{25}$ Prov 17,12. Compárese con Ibn Šabbětay: «Tópate con osa despojada de sus oseznos y manada de lobos de los bosques, pero no con mujer en ocultos aposentos" (A. NAvarro, op. cit., pág. 174).

${ }^{26}$ Prov 28,3.

27 Is 30,28 .

${ }^{28}$ I. DA VIDSON, Šaloš, págs. 27-28.

29 A. Navarro Peiro, op. cit., pág. 192.
} 
estos cuentos, que contiene una curiosa reelaboración de la historia bíblica de Jonás ${ }^{30}$ :

Ejemplo: Había una gran ciudad a la orilla del mar y hete aquí que desde lejos llegaba una nave en cuyo interior se encontraba una mala mujer. Sucedió que el mar se agitó más y más y parecía que la nave iba a quebrarse ${ }^{31}$. Dijeron los hombres: «¿Por quién nos ha venido este mal? ${ }^{32}{ }^{2}$. Encontraron a una mujer mala que dormía en los fondos de la nave y junto a ella espíritus y demonios. La llevaron al capitán y dijeron: "A ésta hemos encontrado, reconócela". Dijo: “Daos prisa, arrojadla al mar y así no moriremos todos nosotros». La echaron al mar, el cual se calmó de su furia ${ }^{33}$. Se la tragó un gran pez y un gran viento huracanado se introdujo en el interior del mar. Se reunieron contra él todos los peces y le presentaron batalla. Lo hirieron unos en la boca, otros en la cola, hasta que casi no quedó aliento en él. Vomitó a la mujer hacia la tierra seca y los peces se calmaron. Entonces cantaron con alegría:

Dios nos ha hecho reír ${ }^{34}$ cuando salió una mujer infame de la fuente del mar.

Si hubiera permanecido entre nosotros, al instante en verdad habríamos perecido y se diría entonces: ¿dónde están? ${ }^{3 s}$

Sucedió que por la tarde, cuando la mujer se dirigió a la ciudad, entró gritando y maldiciendo. Su lengua era como fuego devorador. El bienestar [de la ciudad] ella profanaba, pues he aquí que una plaga comenzó entre el pueblo. Los médicos contemplaban esto asombrados, pues tenían miedo de ello, ya que no sabían qué era. Consultaron para saber la causa a la gente que estaba en el interior, y se presentó un anciano cubierto con un manto que les dijo: "Prestadme atención. Estaba yo a la puerta de la entrada de la ciudad ayer al anochecer y he aquí que entró una mujer con paso ligero, anormal en sus miembros, fea y taciturna. La llamé Mara ${ }^{36}$. Me dijo: ¿Cómo sabes mi nombre?, pues Mara soy y amarga seré

\footnotetext{
${ }^{30}$ Texto hebreo en I. DAvidson, Šalos, págs. 30-31.

${ }^{31}$ Jon $1,11.13$ y 1,4 .

32 Jon 1,7 .

33 Jon 1,15 .

${ }^{34}$ Cf. Gen 21,6.

${ }^{35} \mathrm{Cf}$. Jb 20,7.

36 'Amarga'. Cf. Rt 1,20.
} 
para vosotros. Y yo tuve miedo ante tal cólera. Sucedió por la mañana que todos los hombres cayeron en cama. Ciertamente es cosa sabida que la maldición de la mujer trajo sobre ellos el mal". Entonces dijeron los médicos: «Hemos hallado la verdad y la verdad enseña que no hay remedio contra una mujer mala". $Y$ escribieron en los antiguos libros de medicina estos versos:

Para toda enfermedad y dolencia hay una cura

y para el veneno bálsamo curativo y medicación, remedio no hay para la mujer mala

que devora a todos los hombres con voracidad ${ }^{37}$.

\section{RESUMEN}

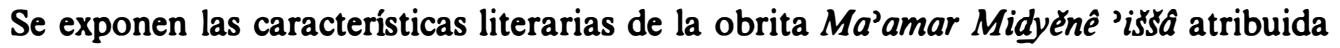
a Maimon Gallipapa (s. XIV) y se compara con el Minhat Yěhudâ de Yěhudah Ibn Šabbětay (ss. XII-XIII), señalando sus coincidencias y discrepancias.

\section{SUMMARY}

The literary features of the small work Ma'amar Midyenê 'išsâ attributed to Maimon Gallipapa (14th century) are analysed in this paper, pointing out the relation between this work and the Minhat Yěhudâ of Yěhudah Ibn Šabbětay (12th13th centuries), their agreements and discrepancies.

${ }^{37}$ Compárense estos versos con los de Ibn Šabbětay en el Minhạ Y Y̌̉huda:

Existe una redención para los cautivos y una aurora como final de la noche, curación para los dolores y un límite para toda perfección, alegria tras la fatiga, consuelo para todo duelo, para la angustia y la aflicción tranquilidad y sosiego.

Pero al cautivo de mujer lloradle a causa de su destino.

¡En verdad que el término para la redención de su alma está oculto y no ha sido revelado!

A. NAVArRo, op. cit., pág. 174. 